\title{
Effects of different extraction methods on the recovery yield of bixin from annatto seeds (Bixa orellana L.)
}

\author{
Chuyen V. Hoang ${ }^{1,3 *}$, Thuy T. Ha $^{2}$, \& Eun Jong-Bang ${ }^{3}$ \\ ${ }^{1}$ Department of Food Technology, Ho Chi Minh City University of Technology and Education, Ho Chi \\ Minh City, Vietnam \\ ${ }^{2}$ Faculty of Natural Sciences and Technology, Tay Nguyen University, Buon Ma Thuot City, Vietnam \\ ${ }^{3}$ Department of Food Science and Technology, Chonnam National University, Gwangju, South Korea
}

\begin{abstract}
ARTICLE INFO
Research Paper

Received: August 08, 2019

Revised: September 19, 2019

Accepted: November 11, 2019
\end{abstract}

\section{Keywords}

Acetone

Annatto

Bixin

Sodium hydroxide

Soybean oil

\section{${ }^{*}$ Corresponding author}

Hoang Van Chuyen

Email: baobien35@gmail.com

\begin{abstract}
Bixin is the a principal color component of annatto pigment which is obtained from the seed coat of Bixa orellana L., a tropical shrub. The extraction yield of bixin from annatto seeds using acetone, soybean oil and sodium hydroxide solution with different extraction conditions were investigated in this study. The extraction time, temperature, solid-liquid ratio and light exposure showed significant effects on the bixin yield. The extraction using soybean oil had the lowest bixin yield followed by the extraction using sodium hydroxide solution. The extraction using acetone resulted in the highest extraction yield (68.1\%) after only $40 \mathrm{~min}$. The extraction using soybean oil at $100^{\circ} \mathrm{C}$ led to two-fold bixin yield compared to that operated at $80^{\circ} \mathrm{C}$ while the mild temperature $\left(50^{\circ} \mathrm{C}\right)$ was found to be the most suitable for the extraction using sodium hydroxide solution. The exclusion of light exposure by covering extraction beakers with aluminum foil could significantly improve the bixin extraction yield due to the reduction in bixin degradation. Therefore the extraction using acetone avoiding light exposure is suggested for recovering bixin from annatto seeds.
\end{abstract}

Cited as: Hoang, C. V., Ha, T. T., \& Jong-Bang, E. (2019). Effects of different extraction methods on the recovery yield of bixin from annatto seeds (Bixa orellana L.). The Journal of Agriculture and Development 18(6), 58-65.

\section{Introduction}

Annatto is a natural food colorant providing yellow to red colors depending on the pigment concentration of the solution. Annatto pigment is obtained from the seed coat of Bixa orellana L., a tropical shrub. This tree is native to tropical South America and also being cultivated in many countries of Central America, Africa and South Asia. The fruit of Bixa orellana L. consists of a pod covered with spines. The pod is usually divided into two halves inside and contains small seeds. Fruits become mature after pollination 5-6 months. Annatto trees reach maximum yield at 4-12 years old and can remain productive for more than 20 years. Pigment content of the seeds ranges from 1.5 to $4 \%$ due to variety, cultivation conditions, and postharvest techniques and quality of annatto seeds can be retained for a long time if they are stored in a cool, dark and 
dry place (Bechtold \& Mussak, 2009).

Annatto pigment has been used for over 200 years as a natural colorant for foods. Although the major source of annatto seeds is South and Central America, the main production of commercial annatto pigment is Europe and the United States which was primarily used to color butter and cheese. Currently annatto is used for a variety of foods such as meat and fish products, soft drinks, sugar confectionery, margarine, ice cream and soups. Annatto is ranked as the second most economically important natural color in the world and it is the most frequently used natural color in the food industry in the United Kingdom (Green, 1995; Lauro \& Francis, 2000; Cannon, 2003).

The red pigment is separated from annatto seeds by different techniques like immersion of seeds in hot vegetable oil, dilute alkaline aqueous solutions or organic solvents. In the traditional food recipes, annatto seeds are heated with cooking oil and then the colored oil is decanted and used for preparing rice, soups, and tortillas. At the industrial production, the seeds are immersed in heated vegetable oil to produce bixin slurry and the filtrate can be marketed as a color for high-fat foods. The outer pigment layer of the seeds can also be extracted by mildly alkaline solution, which is then acid precipitated, filtered and dried to give a granular powder of annatto. Solvent extraction of annatto pigment that can produce $80-97 \%$ purity annatto colorant has been developed to satisfy the demand of more concentrated annatto color products. Numerous organic solvents such as chlorinated hydrocarbons, mixtures of ethanol and chloroform, acetone, ethanol, ethyl acetate, hexane, methanol or alcoholic sodium hydroxide have been reported to be suitable for producing annatto concentrates.

The principal color component of annatto pigment is bixin which constitutes more than $80 \%$ of color content (Preston \& Rickard, 1980) of annatto. Bixin is very susceptible with processing conditions such as temperature, light and oxygen which might cause a significant color loss of annatto pigment. A number of studies have focused on the degradation of bixin during processing and storage, and in foods added with annatto pigment. For examples, stability of annatto solution extracted by chloroform to light, air, antioxidants and pro-oxidants has been described by Najar et al. (1988). Light was found as the most destructive agent followed by the pro-oxidant, benzoyl peroxide. Bixin was observed to be more stable at intermediate/higher water activities in a study by Gloria et al. (1995). The effects of processing conditions on the stability of annatto added in to cakes, chegodis, biscuits and fried rice was reported (Prabhakara Rao et al., 2005) and the deep fat fried processing of chegodis caused the maximum loss of bixin (65\%). Beside the effect on color intensity of annatto pigment, the decomposition of bixin produces volatile compounds like m-xylene, toluene and toluic acid (McKeown, 1965) which can cause some negative effects to human health.

Although studies related to techniques for recovering bixin from annatto seeds have been reported, a comprehensive research comparing the effectiveness of different extraction methods using various conditions for the recovery of pigment from this material is limited. Thus the extraction yield of bixin, the principal color component of annatto pigment, obtained from various extraction methods and extraction conditions were investigated in the present study.

\section{Materials and Methods}

\subsection{Materials}

Annatto seeds were purchased from a local market in the Central Highland of Vietnam. Soybean oil (Ottogi) was purchased from a local market in Gwangju, South Korea.

Acetone and sodium hydroxide were supplied by Dea Jung company and pentane was provided by Kanto Chemical Company (Seoul, South Korea); tetrahydrofuran $(\geq 99 \%)$, ethylbenzene $(99.8 \%)$, toluene $(99.8 \%)$, m-xylene $(\geq$ $99 \%$ ), and o-xylene ( $\geq 99 \%)$ were obtained from Sigma-Adrich (Darmstadt, Germany). The other reagents were in analytical grade.

\subsection{Extraction of total bixin content from an- natto seeds}

Bixin content in annatto seed was determined according to the method of Balaswamy et al. (2006). Annatto seeds (2 g) were weighed exactly in a beaker wrapped and covered by aluminum foil to prevent the loss of bixin by effects of light. Pigment in the seeds was then extracted repeatedly by chloroform until total pigment is removed from the seeds (determined by observing color of 
the extracts). During extraction process, the extracts were collected into a brown glass bottle and stored in a refrigerator. The extract was then diluted and measured absorbance at $487 \mathrm{~nm}$ for determining bixin content.

\subsection{Extraction of bixin using different sol- vents}

Extraction by soybean oil: $5 \mathrm{~g}$ of annatto seeds was submerged into a beaker containing soybean oil with stirring at $80^{\circ} \mathrm{C}$ and $100^{\circ} \mathrm{C}$ (Preston \& Rickard, 1980). Extraction by acetone: $5 \mathrm{~g}$ of annatto seeds was extracted by acetone in a beaker with stirring at $50^{\circ} \mathrm{C}$ (Balaswamy et al., 2006).

Extraction by sodium hydroxide solution: $5 \mathrm{~g}$ of annatto seeds was submerged and stirred in a beaker containing $\mathrm{NaOH} 0.1 \mathrm{~N}$ solution at 40, 50 and $60^{\circ} \mathrm{C}$ (Shuhama et al., 2003).

Extraction of bixin from annatto seed in darkness (exclusion of light): Annatto seeds were submerged and stirred in a beaker which was wrapped and covered by aluminum foil to exclude light exposure.

\subsection{Analysis of bixin content in annatto ex- tracts}

The bixin content in the extracts was determined by measuring absorbance solutions at 487 nm using a spectrophotometer (Optizen 2120UV, Mecasys Co.Ltd, Daejeon, South Korea) (Smith, 2006). One milliliter of bixin extract was dissolved in $10 \mathrm{~mL}$ tetrahyrofuran in $100 \mathrm{~mL}$ volumetric flask and then this solution was diluted by acetone to obtain a solution with absorbance ranged from 0.2 to 1.0. Absorbance of the diluted solution was measured in $1 \mathrm{~cm}$ cuvet at $487 \mathrm{~nm}$. The concentration of bixin in solution was calculated based on the extinction coefficient $\left(\mathrm{E}_{1 \%}^{1 \mathrm{~cm}}\right)$ of 3.090, according to following formula:

Bixin concentration $(\%)=$

$$
\frac{\mathrm{A}}{3.090} \times \frac{100,000}{\text { sample weight }(\mathrm{mg})} \times 100
$$

\subsection{Data analysis}

All experiments were performed in triplicates, and the results were expressed as the mean \pm standard deviation. LSD tests were used for comparisons amongst values. Differences were considered to be significantly different at $P<0.05$.

\section{Results and Discussion}

\subsection{Extraction of bixin using sodium hydrox- ide solution}

\subsubsection{Effects of temperature}

Influences of temperature $\left(40,50\right.$, and $\left.60^{\circ} \mathrm{C}\right)$ on the yield of bixin extracted from annatto seeds by sodium hydroxide solution is shown in Figure 1. Temperature showed significant effects on bixin yield at the beginning of the processes. Then only significantly lower yields were observed in the extraction at $40^{\circ} \mathrm{C}$ as compared to that at other temperatures. No significant differences in bixin yield appeared between the processes carried out at 50 and $60^{\circ} \mathrm{C}$. At the extraction time of $100 \mathrm{~min}$, the yield of bixin seemed to reach the plateau when there were no significant changes in the yield compared to that at the extraction time of $80 \mathrm{~min}$ for extractions at $50^{\circ} \mathrm{C}$ and $60^{\circ} \mathrm{C}$. Besides, bixin yield of extraction at $40^{\circ} \mathrm{C}$ also achieved a similar level with these processes. These results suggested that it is better to carry out the extraction of annatto pigment by sodium hydroxide solution at $50^{\circ} \mathrm{C}$ because the extraction at this temperature can achieve significantly higher bixin extraction yield than that of extraction at $40^{\circ} \mathrm{C}$. Furthermore, this extraction can also reduce the loss of bixin caused by high temperature. The significant effect of temperature on the degradation of bixin was reported in a number of previous studies such as Shuhama et al. (2003), Balaswamy et al. (2006) and Silva et al. (2007).

\subsubsection{Effects of solid-liquid ratio on bixin ex- traction yield}

The difference in volume of sodium hydroxide solution had no significant effects on the extraction yield of bixin from annatto seed at the extraction time of 20 and 40 min (Figure 2). However, at 60 minutes of the process, the high volume of sodium hydroxide solution (ratio of 1:10 $(\mathrm{g} / \mathrm{mL}))$ showed a significantly higher extraction yield compared to the other solid-liquid ratios. The 60 min extraction at this ratio obtained $7 \%$ higher bixin yield than that at $40 \mathrm{~min}$ (from $29.7 \%$ to $36.7 \%$ ), whereas the ratios of $1: 5$ and $1: 2(\mathrm{~g} / \mathrm{mL})$ had no significant differences in bixin yield with only small increases of 6 and $3.9 \%$, respectively. Therefore, if the extraction is oper- 


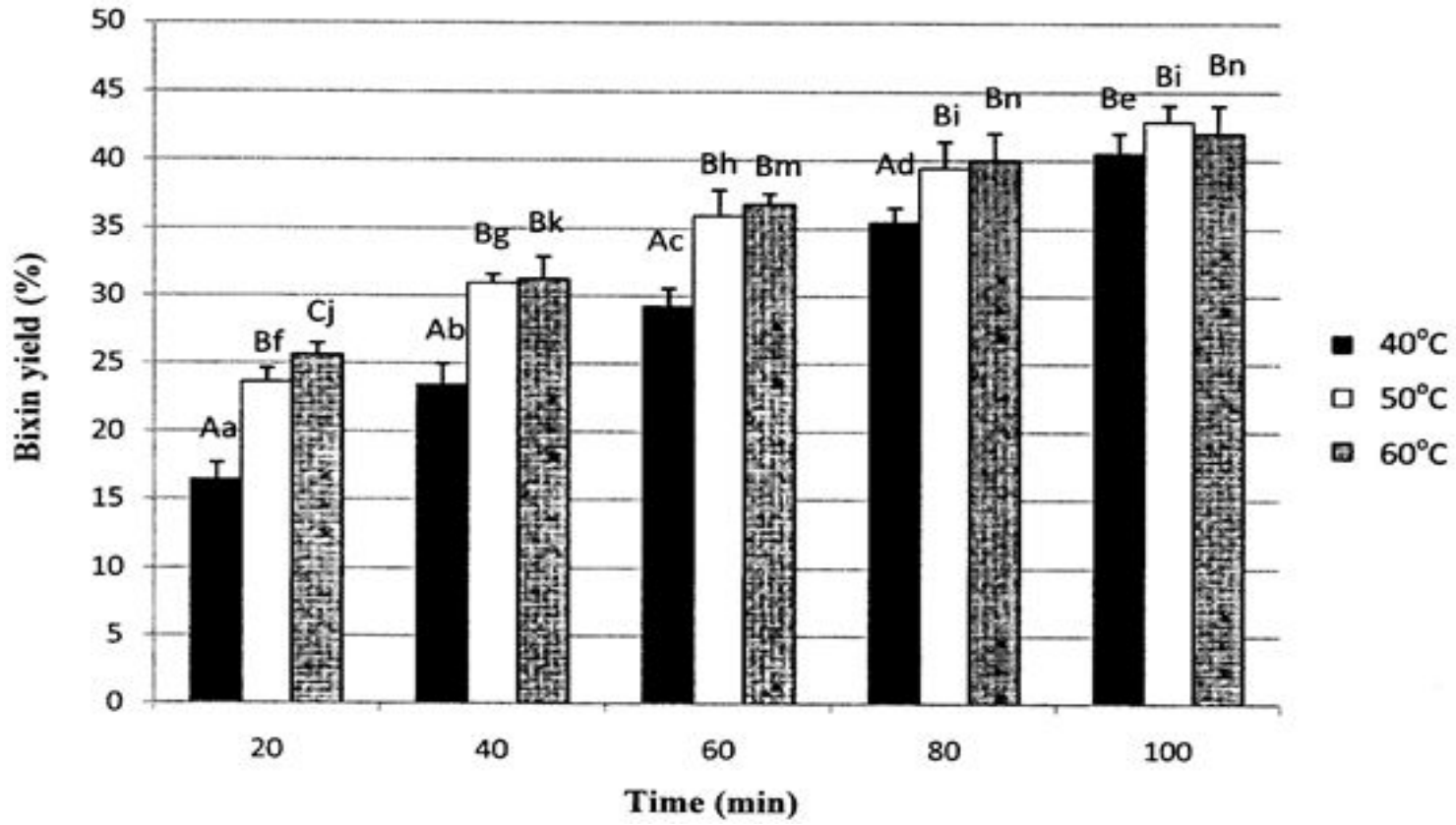

Figure 1. Extraction yield of bixin at different temperatures by sodium hydroxide solution. Different capital letters show significant differences in bixin yield among different temperatures at the same time $(P<0.05)$.

Different small letters show significant differences in bixin yield among different time intervals of each extraction process $(P<0.05)$.

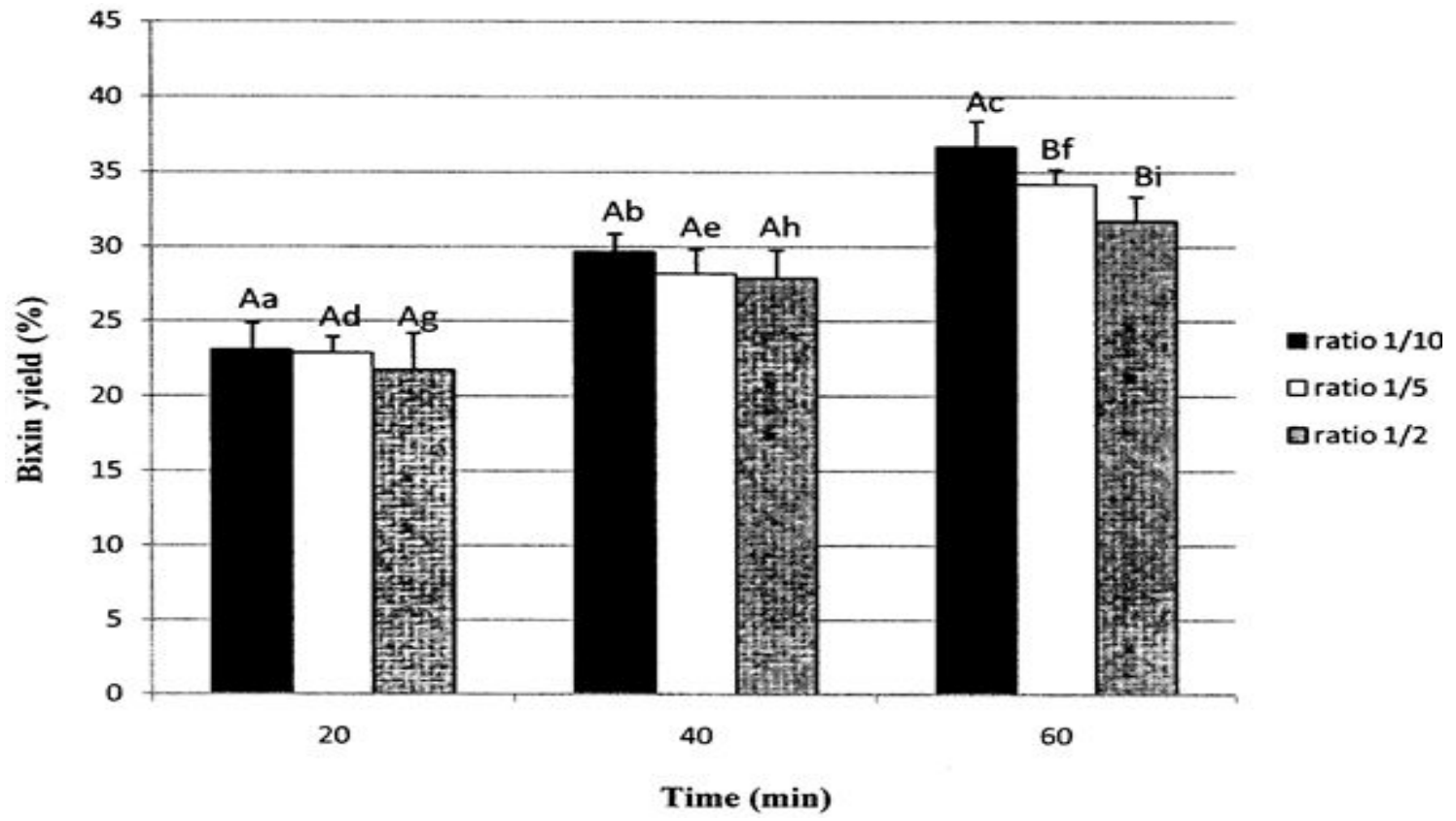

Figure 2. Extraction yield of bixin using sodium hydroxide solution with different solid-liquid ratio.

Different capital letters show significant differences in bixin yield among different solid-liquid ratios at the same time $(P<0.05)$.

Different small letters show significant differences in bixin yield between different times of each extraction using a solid-liquid ratio $(P<0.05)$. 


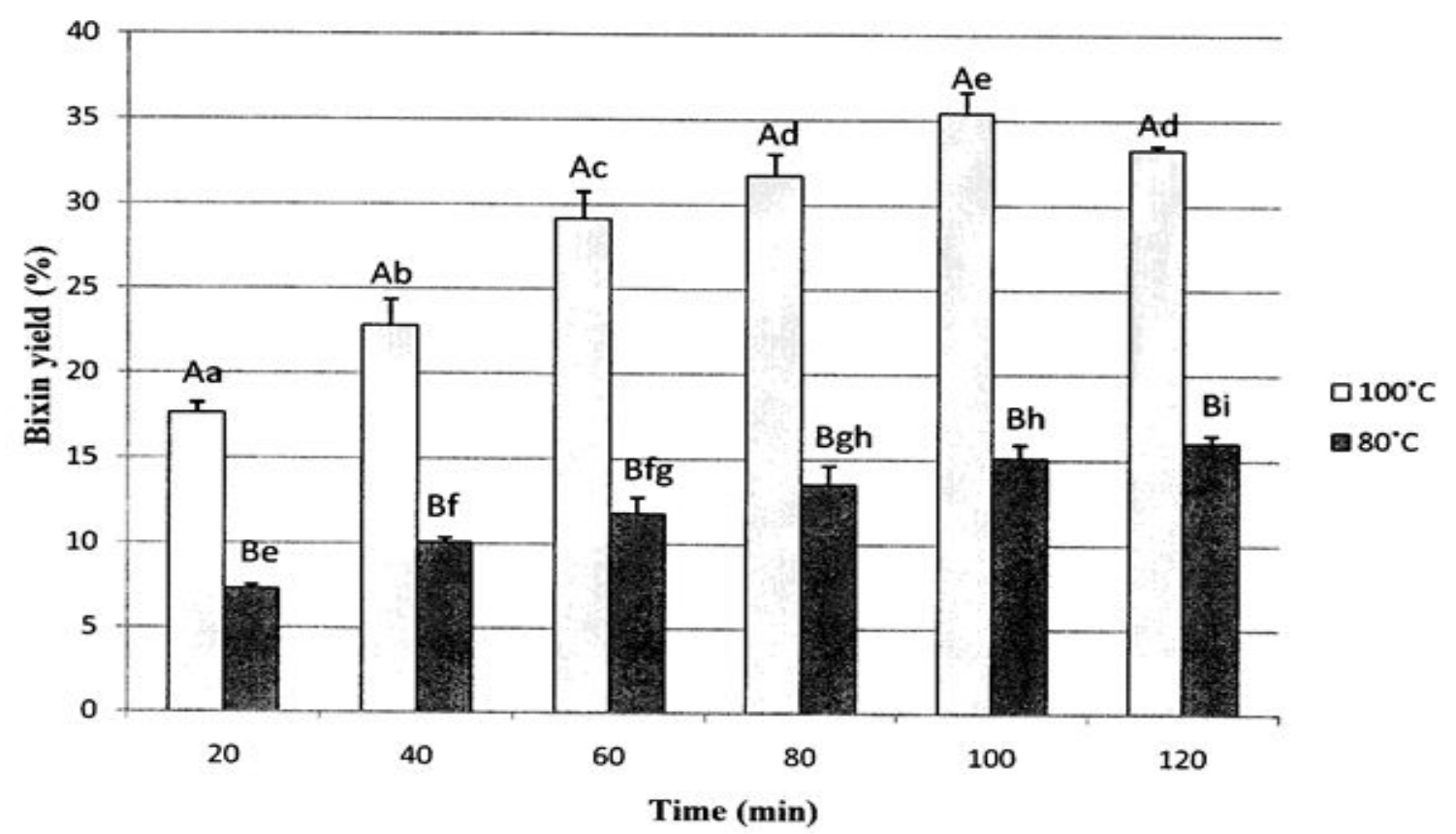

Figure 3. Extraction yield of bixin by soybean oil at $80^{\circ} \mathrm{C}$ and $100^{\circ} \mathrm{C}$.

Different capital letters show significant differences in bixin yield between extraction temperatures at the same time $(P<0.05)$.

Different small letters show significant differences in bixin yield among different times using an extraction temperature $(P<0.05)$.

ated within $40 \mathrm{~min}$, the volume of solution could be considerably reduced without any decrease in bixin extraction yield. This reduction can resulted in a significant energy saving for evaporation of water to produce commercial annatto powder from aqueous alkaline solution of annatto (Shuhama et al., 2003).

\subsection{Extraction of bixin using soybean oil}

\subsubsection{Effects of temperature on extraction yield of bixin}

Extraction temperature showed significant influences on the bixin yield in the extraction method using soybean oil (Figure 3). When temperature dropped only $20^{\circ} \mathrm{C}$ (from $100^{\circ} \mathrm{C}$ to $80^{\circ} \mathrm{C}$ ), the extraction yields decreased extensively. The extraction at $100^{\circ} \mathrm{C}$ achieved more than twice bixin yield compared to that of the extraction at $80^{\circ} \mathrm{C}$ throughout $120 \mathrm{~min}$ of extraction time. The increases in bixin yield after every $20 \mathrm{~min}$ at this temperature were also significantly higher than those of $80^{\circ} \mathrm{C}$ extraction. The low bixin extraction yield achieved by soybean oil may not be caused by the solubility of this compound, but because of the severe degradation at high temperature. Consequently, it is better to improve bixin extraction yield in this method by reducing bixin loss than by increasing its solubility based on the increase of soybean oil temperature. These results suggested that extraction at $100^{\circ} \mathrm{C}$ may be a good option, which not only improve yield of bixin but also reduce the content of undesirable compounds caused by bixin degradation in the extracts.

\subsubsection{Effects of solid-liquid ratio and light on extraction yield of bixin}

Figure 4 shows bixin yields extracted by soybean oil at the ratios 1:4 and 1:2 $(\mathrm{g} / \mathrm{mL})$ and yield of bixin extracted in the darkness at the ratio of $1: 2(\mathrm{~g} / \mathrm{mL})$. Surprisingly, the extraction yield derived from the lower ratio (1:2) was significantly higher than that of the higher ratio during 60 min of extraction. This result may be explained by the lower decomposition of bixin in the higher concentrated solutions, which were obtained from lower ratio of seed weight per soybean oil volume. As expected, the extraction in the darkness led to a greater extraction yield of bixin compared to 


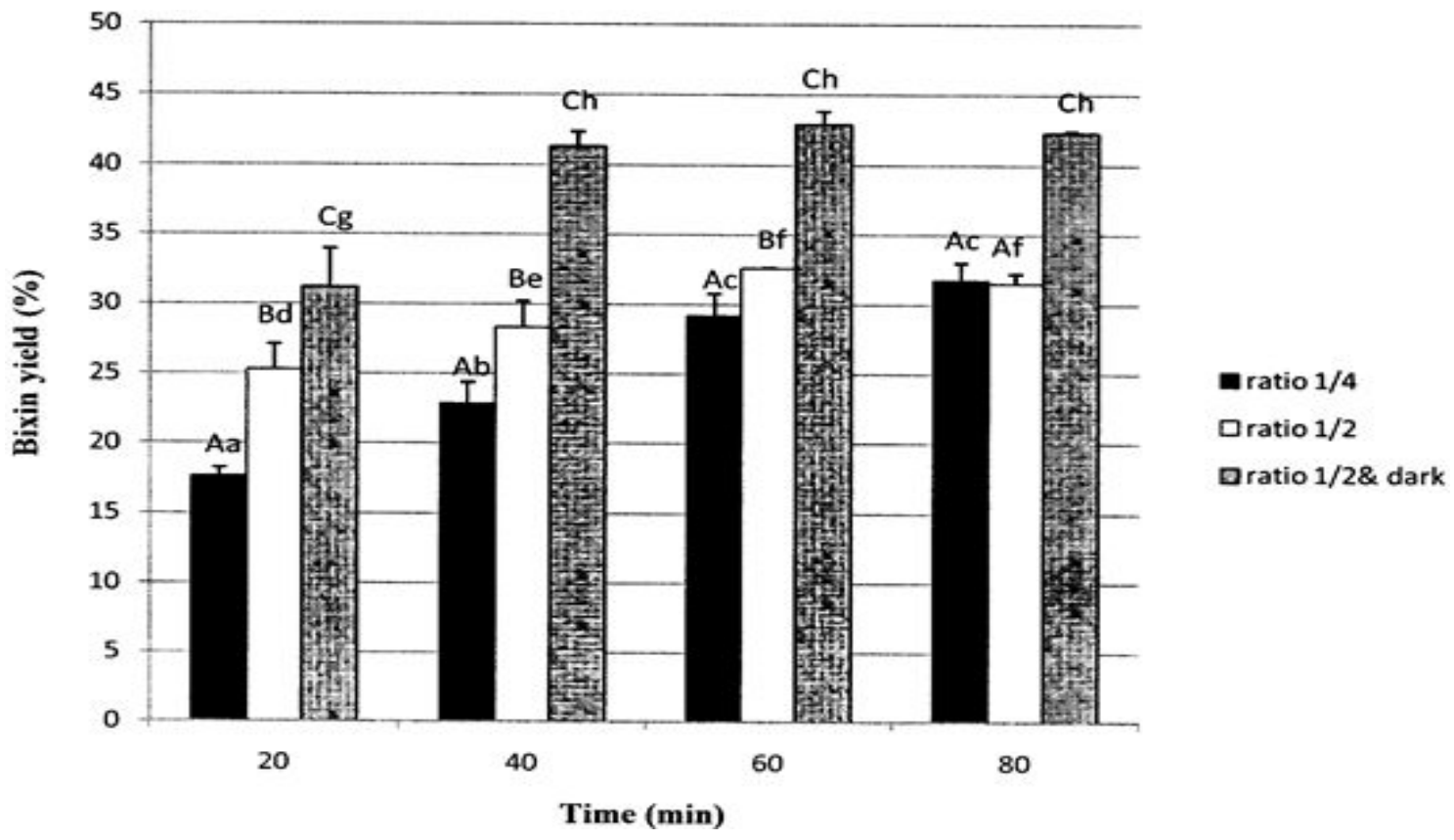

Figure 4. Extraction yield of bixin using soybean oil with different solid-liquid ratio and exclusion of daylight Different capital letters show significant differences in bixin yield between extraction conditions at the same time $(P<0.05)$.

Different small letters show significant differences in bixin yield between different times of an extraction condition $(P<0.05)$.

the extraction exposed to daylight. Furthermore, this process reached the maximum yield $(41.3 \%)$ after only $40 \mathrm{~min}$ of extraction. This greater extraction yield might be due to the significant decrease in bixin degradation with the absence of daylight, because all other conditions were similar except the exclusion of daylight. These results are in agreements with the previous reports, which showed the predominant impact of light among various factors on the degradation of bixin in annatto colors and foods containing this compound (Najar et al., 1988; Balaswamy et al., 2006).

\subsection{Extraction of bixin using acetone}

\subsubsection{Effects of solvent volume and light to bixin yield extracted by submerging in acetone at $50^{\circ} \mathrm{C}$}

Bixin yields extracted with different ratios of annatto seed weight per volume of acetone and in darkness $50^{\circ} \mathrm{C}$ are illustrated in Figure 5. The immersion of annatto seed in acetone for $60 \mathrm{~min}$ resulted in a greater amount of extracted bixin compared to the methods using sodium hydroxide solution and soybean oil. This method achieved a yield of $63 \%$ at 20 min of extraction while that was lower than $25 \%$ in the extraction using the other solvents. The extraction yield obtained by submerging in acetone could reach to the maximum value of $68.1 \%$ after only $40 \mathrm{~min}$ of the extraction time.

The volume of acetone showed no significant effects on bixin extraction yield at the beginning of process, but the decrease in volume of acetone (ratio of 1:2 g/mL) indicated a considerable decrease in extraction yield at 60 min of extraction time. However, the exclusion of light (extraction in beakers covered by aluminum foil) at this solidliquid ratio $(1: 2 \mathrm{~g} / \mathrm{mL})$ could improve the bixin extraction yield to a comparable value of that using the ratio of $1: 4(\mathrm{~g} / \mathrm{mL})$. Therefore, it seems to have no significant decrease in bixin extraction yield if the ratio of annatto seed weight per acetone volume decreases to $1: 2(\mathrm{~g} / \mathrm{mL})$.

\section{Conclusions}

In this study, the extraction yield of bixin from annatto seeds using acetone, soybean oil and sodium hydroxide solution with different ex- 


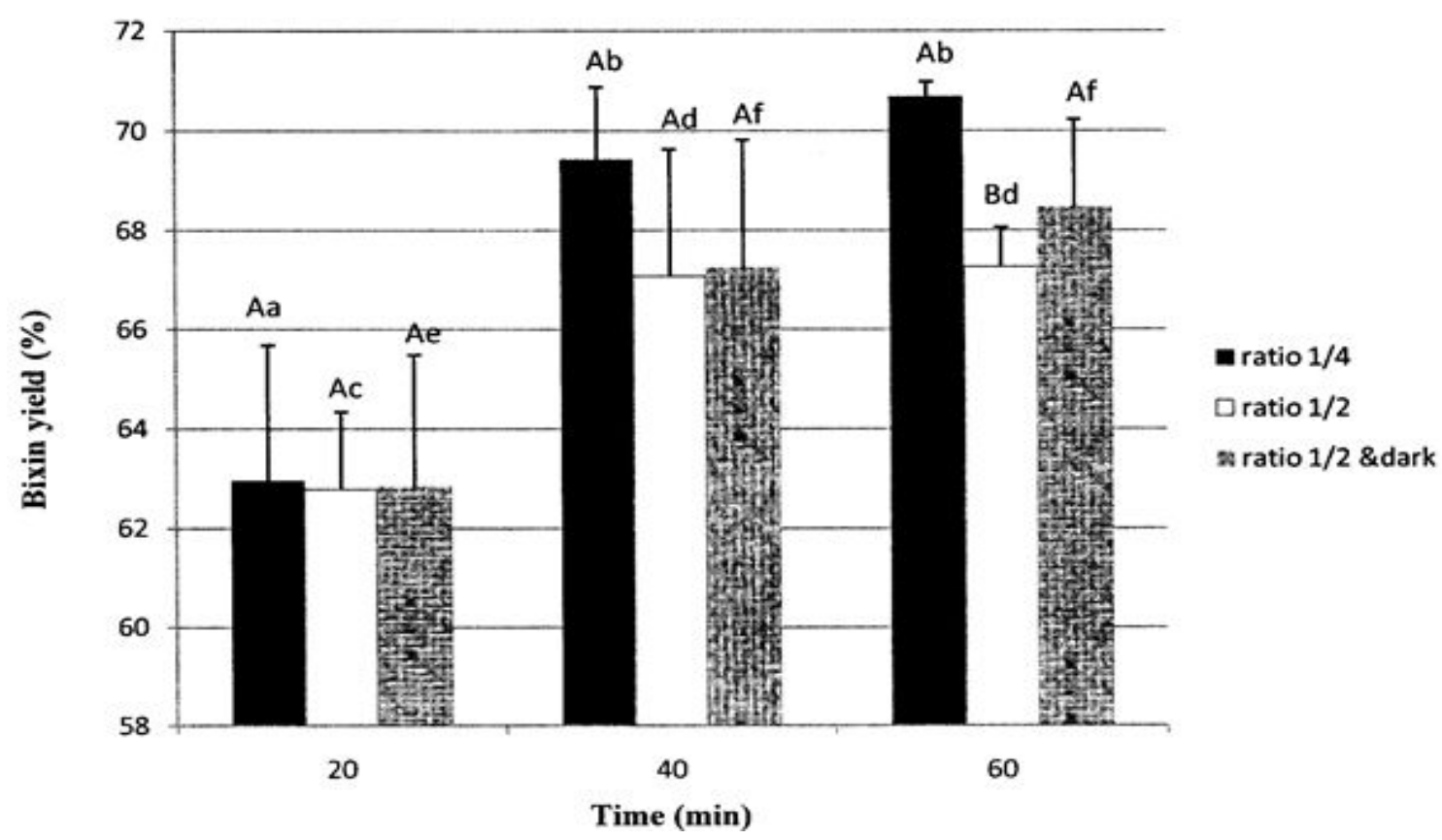

Figure 5. Yield of bixin extracted by submerging in acetone at $50^{\circ} \mathrm{C}$ with different ratio of annatto seed weight/volume of acetone and in the dark condition.

Different capital letters show significant differences in bixin yield between extraction conditions at the same time $(P<0.05)$.

Different small letters show significant differences in bixin yield between different times of an extraction condition $(P<0.05)$.

traction conditions were investigated. The extraction time, temperature, solid-liquid ratio and light exposure showed significant effects on the bixin yield. The extraction using soybean oil had the lowest bixin yield followed by the extraction using sodium hydroxide solution. The extraction using acetone resulted in the highest extraction yield (68.1\%) after only $40 \mathrm{~min}$. The extraction using soybean oil at $100^{\circ} \mathrm{C}$ led to two-fold bixin yield compared to that operated at $80^{\circ} \mathrm{C}$ while the mild temperature $\left(50^{\circ} \mathrm{C}\right)$ was found to be the most suitable for the extraction using sodium hydroxide solution. The exclusion of light exposure by covering extraction beakers with aluminum foil could significantly improve the bixin extraction yield due to the reduction in bixin degradation. The results suggest that the extraction using acetone with exclusion of light exposure is the most suitable for recovering pigment from annatto seeds.

\section{Conflict of interest declaration}

The authors declare no conflict of interest.

\section{References}

Balaswamy, K., Prabhakara Rao, P. G., Satyanarayana, A., \& Rao, D. G. (2006). Stability of bixin in annatto oleoresin and dye powder during storage. $L W T$ - Food Science and Technology 39, 952-956.

Bechtold, T., \& Mussak, R. (2009). Handbook of natural colorants. New Jersey, USA: John Wiley \& Sons.

Cannon, J., Cannon, M., \& Dalby-Quenet, G. (2003). Dye plants and dyeing. Virginia, USA: Timber Press.

Gloria, M. B. A., Vale, S. A., \& Bobbio P. A. (1995). Effect of water activity on the stability of bixin in an annatto extract-microcrystalline cellulose model system. Food Chemistry 52, 389-391.

Green, C. L. (1995). Natural colourants and dyestuffs report. Rome, Italy: FAO.

Lauro, G. J., \& Francis, F. J. (2000). Natural food colorant. New York City, USA: Marcel Dekker.

McKeown, G. G. (1963). Composition of oil-soluble annatto food colours II. Thermal degradation of bixin. Journal - Association of Official Analytical Chemists 46(5), 790-796.

Najar, S. V., Bobbio, F. O., \& Bobbio, P. A. (1988). Effects of light, air, anti-oxidants and pro-oxidants on annatto extracts (Bixa orellana). Food Chemistry 29, 283-289. 
Prabhakara Rao, P. G., Jyothirmayi, T., Balaswamy, K., Satyanarayana, A., \& Rao, D. G. (2005). Effect of processing conditions on the stabilityof annatto (Bixa orellana L.) dye incorporated into some foods. $L W T$ Food Science and Technology 38(7), 779-784.

Preston, H. D., \& Rickard, M. D. (1980). Extraction and chemistry of annatto. Food Chemistry 5, 47-56.

Shuhama, I. K., Aguiar, M. L., Oliveira, W. P., \& Freitas, L. A. P. (2003). Experimental production of annatto powders in spouted bed dryer. Journal of Food Engineering 59(1), 93-97.
Silva, G. S., Souza, A. G., Botelho, J. R., Silva, M. C. D., \& Silva, T. M. S. (2007). Kinetics study of norbixin's first stage thermal decomposition, using dynamic method. Journal of Thermal Analysis and Calorimetry 87, 871-874.

Smith, J. (2006). Annatto extracts. 67th JECFA - Chemical and Technical Assessment 21, 1-13. 